\title{
RNA interference-mediated targeting of DKK1 gene expression in Ishikawa endometrial carcinoma cells causes increased tumor cell invasion and migration
}

\author{
NUO YI ${ }^{1}$, QIN-PING LIAO ${ }^{2}$, ZHEN-HUA LI $^{1}$, BAO-JIANG XIE ${ }^{3}$, YU-HONG HU ${ }^{1}$, WEI YI ${ }^{1}$ and MIN LIU ${ }^{1}$ \\ ${ }^{1}$ Department of Obstetrics and Gynecology, Beijing Ditan Hospital, Capital Medical University, Beijing 100015; \\ ${ }^{2}$ Department of Obstetrics and Gynecology, Peking University First Hospital, Beijing 100034; \\ ${ }^{3}$ Department of Surgery, Beijing International Studies University Hospital, Beijing 100024, P.R. China
}

Received January 27, 2013; Accepted May 30, 2013

DOI: $10.3892 / 01.2013 .1439$

\begin{abstract}
The Wnt signaling pathway plays an essential role in tumor invasion and migration. DKK1 functions as an important inhibitor of the pathway and represents a promising target for cancer therapy. The aim of the present study was to determine the role of DKK1 in endometrial carcinoma (EC) cell invasion and migration using RNA interference (RNAi) technology. Ishikawa EC cells were transfected at high efficiency with specific DKK1 siRNA. RT-PCR and western blot analysis were used to determine the mRNA and protein levels of DKK1, $\beta$-catenin and metalloproteinase 14 (MMP14) in siRNA-treated and -untreated cells. In addition, the invasion and migration of the EC cells were detected by invasion and migration assays. Transient transfection of DKK1 siRNA significantly inhibited the mRNA and protein levels of DKK1. Markedly increased cell invasion and migration was observed following treatment with DKK1 siRNA when compared with the negative control siRNA-treated and siRNA-untreated cells. The knockdown of DKK1 also elevated the mRNA and protein levels of $\beta$-catenin and MMP14 involved in the Wnt signaling pathway, indicating that targeting this gene may promote intracellular Wnt signal transduction and thus, accelerate EC cell invasion and migration in vitro. The RNAi-mediated targeting of DKK1 gene expression in Ishikawa EC cells resulted in increased tumor cell invasion and migration. DKK1 was identified as an inhibitor of EC cell invasion and migration via its novel role in the Wnt signaling pathway. Targeting DKK1 may
\end{abstract}

Correspondence to: Dr Zhen-Hua Li, Department of Obstetrics and Gynecology, Beijing Ditan Hospital, Capital Medical University, 8 Jingshun East Street, Beijing 100015, P.R. China

E-mail: yinuo_76@126.com

Abbreviations: ECM, extracellular matrix; RNAi, RNA interference; MMPs, metalloproteinases; EC, endometrial carcinoma

Key words: $\beta$-catenin, DKK1, endometrial carcinoma, invasion, migration, MMP14, RNAi therefore represent an effective anti-invasion and -migration strategy for the treatment of EC.

\section{Introduction}

Endometrial carcinoma (EC) is a common malignant tumor of the female genital tract, which has notably increased in incidence over recent years (1). Tumor invasion and migration are characteristic features in the majority of malignant tumors, including EC $(2,3)$. Previous studies have identified that abnormalities in the Wnt signaling pathway contribute to tumorigenesis in favor of tumor migration, invasion and metastasis (4-8). DKK1, an inhibitor of the Wnt signaling pathway, has been identified in the invasion and migration of specific benign and malignant tissues. $\beta$-catenin is a pivotal molecule in the Wnt signaling pathway and metalloproteinase 14 (MMP14) is a downstream target gene. In addition, these molecules have been identified as mediators of tumor invasion and migration. Therefore, in the current study, $\beta$-catenin and MMP14 were targeted using DKK1 siRNA to identify the effects of DKK1 on the invasion and migration of EC cells.

\section{Materials and methods}

Cell culture. Ishikawa EC cell lines were obtained from the American Type Culture Collection (Manassas, VA, USA). The cells were maintained in DMEM/F12 medium (Invitrogen Life Technologies, Carlsbad, CA, USA) supplemented with $10 \%$ fetal bovine serum (GE Healthcare, Amersham, UK), $100 \mu \mathrm{g} / \mathrm{ml}$ penicillin and $100 \mu \mathrm{g} / \mathrm{ml}$ streptomycin in a humidified atmosphere containing $5 \% \mathrm{CO}_{2}$ at $37^{\circ} \mathrm{C}$. Routine testing confirmed that the cells were free of mycoplasma and viral contaminants. The cells were subcultured every 2 days at a ratio of 1:2.

Cell transfection. The following primer sequences for siRNAs targeting human $D K K 1$ were used: i) (RNA)-AUA GCG UUG GAA UUG AGA ACC GAG U; ii) (RNA)-ACU CGG UUC UCA AUU CCA ACG CUA U; and iii) (RNA)-AAU CCU GAG GCA CAG UCU GAU GAC C. Stealth ${ }^{\mathrm{TM}}$ RNAi Negative Control Med GC was used as a negative control for 
the siRNA (siRNA sequences were obtained from Invitrogen Life Technologies).

Transfection conditions. The EC cells were transfected with DKK1 siRNA or negative control siRNA or untransfected (DKK1 RNAi, control and blank groups, respectively). The EC cells were then seeded in $35-\mathrm{mm}$ culture dishes at $1 \times 10^{6}$ cells/well prior to transfection with DKK1 siRNA or negative control siRNA using Lipofectamine 2000 reagent, according to the manufacturer's instructions. Lipofectamine $2000(5 \mu \mathrm{l})$ diluted in $250 \mu \mathrm{l}$ Opti-MEM was prepared. In addition, $10 \mu 1$ DKK1 siRNA $(20 \mu \mathrm{M})$ and $10 \mu 1$ negative control siRNA $(20 \mu \mathrm{M})$ were diluted with $250 \mu \mathrm{l}$ Opti-MEM and incubated for $20 \mathrm{~min}$. The $500 \mu \mathrm{l}$ complexes of Lipofectamine 2000 and siRNA plus $1,500 \mu 1 \mathrm{DMEM} / \mathrm{F} 12$ were introduced to 35-mm culture dishes and incubated in a humidified atmosphere containing $5 \% \mathrm{CO}_{2}$ at $37^{\circ} \mathrm{C}$. After 5-6 h, the medium was replaced with $10 \%$ serum-supplemented DMEM/F12 and the cells were incubated for 24-96 $\mathrm{h}$ for further use in various procedures (all reagents were obtained from Invitrogen Life Technologies).

Transfection efficiency. BLOCK iT ${ }^{\mathrm{TM}}$ fluorescent oligos (Invitrogen Life Technologies) were transfected into the cells of the DKK1 RNAi and control groups to ensure the successful transfection of siRNA into the cells.

Silencing efficiency. The silencing efficiency was determined by RT-PCR and western blot analysis using DKK1-specific primers and antibodies. Subsequent experiments focused on the primer previously described as primer ii in the cell transfection methods for siRNAs targeting human DKK1, since it was identified as the most effective for inhibiting DKK1 expression.

Semi-quantitative RT-PCR analysis. mRNA levels of DKK1, $\beta$-catenin, MMP14 and GAPDH (internal control) were determined by RT-PCR. Following cell incubation, total RNA was extracted from the cells using TRIzol ${ }^{\circledR}$ reagent (Invitrogen Life Technologies). The reverse transcription reaction was set up using RT reaction mix (Promega Corporation, Madison, WI, USA) and the resultant cDNA was used for PCR. The following primers for DKK1, $\beta$-catenin, MMP14 and GAPDH were used: i) DKK1 sense, 5'-CTGCATGCGTCACGCTATGT-3' and antisense, 5'-TCCTCGGAAATGATTTTGATCA-3'; ii) $\beta$-catenin sense, 5'-CGGGATGTTCACAACCGAAT-3' and antisense, 5'-TTGGATGTTTTCAATGGGAGAA-3'; iii) MMP14 sense, 5'-CAGGGTCTCAAATGGCAACA-3' and antisense, 5'-TTGCGAATGGCCTCGTATG-3'; and iv) GAPDH sense, 5'-CAGTCAGCCGCATCTTCTTTT-3' and antisense, 5'-GTG ACCAGGCGCCCAATAC-3'. Experiments were performed in triplicate.

Western blot analysis. Protein levels of intracellular DKK1, active- $\beta$-catenin, MMP14 and $\beta$-actin (internal control) were detected by western blot analysis. When the cells reached $80-90 \%$ confluence, they were lysed in lysis buffer with protease inhibitors at $4^{\circ} \mathrm{C}$. Cell lysates were also collected and protein concentrations were determined using the Bradford method. The lysates were cleared by centrifugation and quantified using the DC protein assay (Bio-Rad, Hercules, CA, USA).
The protein samples $(50 \mu \mathrm{g})$ were boiled for $5 \mathrm{~min}$ prior to being loaded onto 10\% SDS-PAGE. Following electrophoresis, proteins were transferred onto a nitrocellulose membrane (Pall Corp., Washington, NY, USA). The membranes were blocked with 5\% skimmed milk in PBS and probed with primary antibodies overnight at $4^{\circ} \mathrm{C}$. Horseradish peroxidase-conjugated secondary antibodies (1:5,000; Santa Cruz Biotechnology, Inc., Santa Cruz, CA, USA) were used and the membranes were developed following an enhanced chemiluminescence detection protocol (Santa Cruz Biotechnology, Inc.). The following primary antibodies and dilutions with blocking solution were used: DKK1 (mouse monoclonal, 1:300; Abnova, Taipai City, Taiwan); active- $\beta$-catenin (mouse monoclonal, 1:500; Upstate Biotechnology, Lake Placid, NY, USA); MMP14 (rabbit polyclonal, 1:300; Abcam, Cambridge, UK) and $\beta$-actin (mouse monoclonal, 1:1,000; Santa Cruz Biotechnology, Inc.). All experiments were performed in triplicate.

Invasion assay. An invasion assay was performed using the Transwell chamber assay according to previous studies (9-11), with modifications. Briefly, Matrigel matrix $(1: 10 \mathrm{v} / \mathrm{v}, 1 \mathrm{mg} / \mathrm{ml}$; BD Biosciences, Franklin Lakes, NJ, USA) was diluted in serumfree DMEM/F12. Then, the diluted Matrigel matrix was addd to the upper wells of a 24-well transwell plate (polycarbonate membranes with an $8-\mu \mathrm{m}$ pore size; Millipore, Billerica, MA, USA) and incubated for 5-6 h at room temperature. The cells of the DKK1 RNAi and blank groups were trypsinized, washed and resuspended. Viable cells were added to the upper wells at a density of $2 \times 10^{5}$ cells/well with $300 \mu \mathrm{l}$ serum-free DMEM/F12, whilst $500 \mu \mathrm{l}$ serum-supplemented DMEM/F12 was filled into the lower wells. Plates were incubated at $37^{\circ} \mathrm{C}$ for $48 \mathrm{~h}$, then non-invaded cells on top of the transwell were scraped off with a cotton swab. The cells in the chambers were maintained in an incubator at $37^{\circ} \mathrm{C}$ and allowed to migrate for $48 \mathrm{~h}$. After $48 \mathrm{~h}$, the non-migrated cells in the upper compartments were scraped carefully with cotton swabs. Migrated cells adhering to the lower surface of the membranes were fixed with methanol and stained with hematoxylin and eosin. The membranes were excised from the insert and mounted onto glass slides for light microscopic analysis, and migrated cells (penetrating Matrigel matrix and pores) were counted (magnification, x20) from ten randomly selected fields. Each sample was assayed in triplicate.

Migration assay. A migration assay was performed following the method for the invasion assay, with the exception of the exclusion of the Matrigel matrix and the use of polycarbonate membranes only.

Statistical analysis. Data are presented as the mean \pm SD. Statistical analyses were performed using SAS Version 9 (SAS Institute Inc., Cary, NC, USA). P<0.05 was considered to indicate a statistically significant difference. Quantitative analyses were performed using the Student's t-test for RT-PCR, western blot analysis and invasion and migration assay results among the three groups.

\section{Results}

Effect of DKK1 siRNA on DKK1 mRNA levels. The EC cells were transfected successfully with DKK1 and negative control 
A

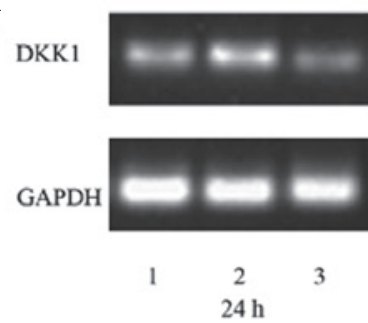

$\mathbf{E}$

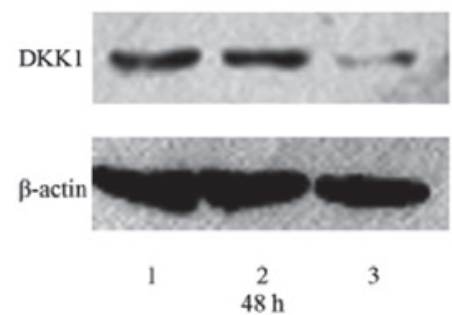

B

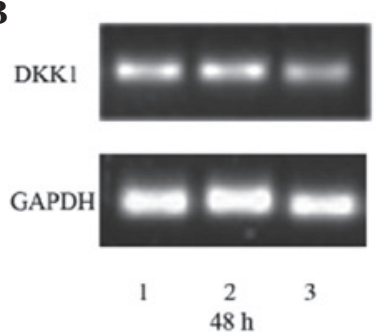

F

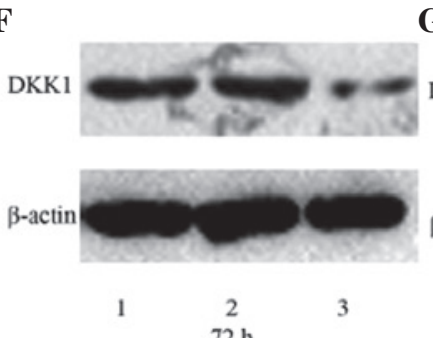

C

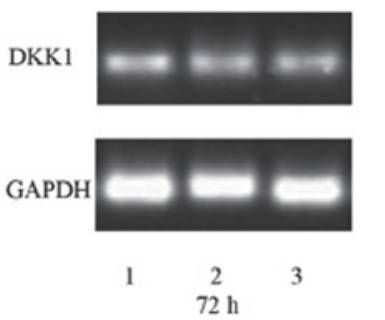

G

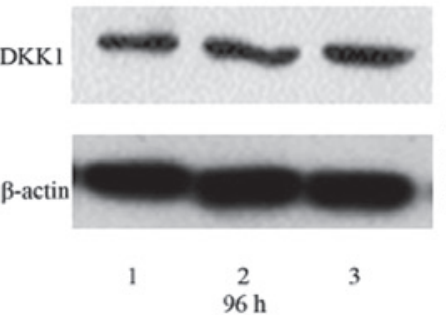

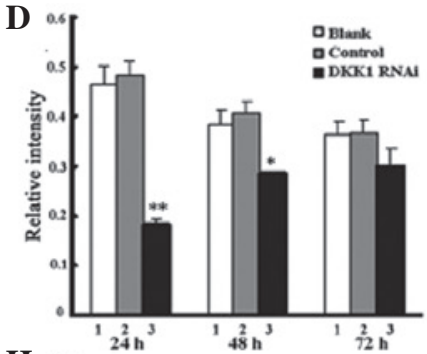

H

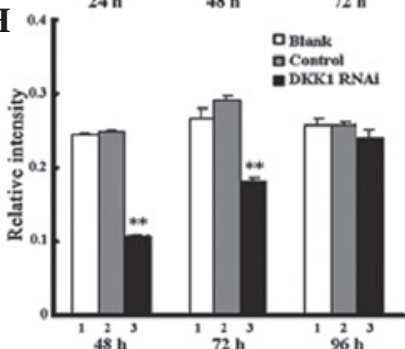

Figure 1. Effect of DKK1 siRNA on mRNA and protein levels of DKK1. Total cell extract levels of DKK1 mRNA in the three groups were measured by RT-PCR at (A) 24, (B) 48 and (C) $72 \mathrm{~h}$. (D) Data are presented as density of DKK1/GAPDH. DKK1 protein levels of cell lysates were detected by western blot analysis at (E) 48, (F) 72 and (G) 96 h. (H) Data are presented as density of DKK1/ $\beta$-actin. ${ }^{*} \mathrm{P}<0.05$ and ${ }^{* *} \mathrm{P}<0.001$, vs. blank group. 1, blank; 2, control; and 3, DKK1 RNAi groups. RT-PCR, reverse transcription polymerase chain reaction.

Table I. DKK1 mRNA levels in the three groups at 24, 48 and $72 \mathrm{~h}$.

\begin{tabular}{lccc}
\hline Groups & $24 \mathrm{~h}$ & $48 \mathrm{~h}$ & $72 \mathrm{~h}$ \\
\hline Blank & $0.465 \pm 0.039$ & $0.385 \pm 0.027$ & $0.363 \pm 0.029$ \\
Control & $0.485 \pm 0.027$ & $0.408 \pm 0.025$ & $0.368 \pm 0.026$ \\
DKK1 RNAi & $0.179 \pm 0.013^{\mathrm{a}}$ & $0.286 \pm 0.003^{\mathrm{b}}$ & $0.301 \pm 0.035$
\end{tabular}

Data are presented as density of DKK1/GAPDH. ${ }^{\text {a }} \mathrm{P}<0.001$ and ${ }^{\mathrm{b}} \mathrm{P}<0.05$, vs. blank group.

siRNAs with high efficiency. DKK1 mRNA levels in total cell extracts were measured by semi-quantitative RT-PCR. Negligible changes in DKK1 mRNA levels were identified in the blank and control groups, however, in the DKK1 RNAi group, the DKK1 mRNA levels showed a decrease between 24, 48 and $72 \mathrm{~h}$ (61.47, 25.79 and $17.04 \%$, respectively, vs. blank). In the DKK1 RNAi group, DKK1 gene expression was significantly inhibited between 24 and $48 \mathrm{~h}$, however, there was no marked difference after $72 \mathrm{~h}$. mRNA levels of GAPDH, as a loading control, were also analyzed, however, no changes were observed (Fig. 1 and Table I).

Effect of DKK1 siRNA on DKK1 protein level. The levels of DKK1 protein in DKK1 siRNA-treated cells were identified to significantly decrease between 48,72 and $96 \mathrm{~h}(56.74,31.64$ and $7.17 \%$, respectively, vs. blank group) when compared with the untreated and control-treated cells. Inhibition was identified as statistically significant between 48 and $72 \mathrm{~h}$, however, no significant difference was identified after $96 \mathrm{~h}$. No change in the protein levels of $\beta$-actin, which served as a loading control, were identified. In addition, no significant differences were identified in protein levels in the blank and control groups (Fig. 1 and Table II).
Table II. DKK1 protein levels in the three groups at 48,72 and $96 \mathrm{~h}$.

\begin{tabular}{lccc}
\hline Groups & $48 \mathrm{~h}$ & $72 \mathrm{~h}$ & $96 \mathrm{~h}$ \\
\hline Blank & $0.246 \pm 0.002$ & $0.266 \pm 0.015$ & $0.251 \pm 0.005$ \\
Control & $0.250 \pm 0.002$ & $0.292 \pm 0.006$ & $0.258 \pm 0.006$ \\
DKK1 RNAi & $0.107 \pm 0.001^{\mathrm{a}}$ & $0.182 \pm 0.003^{\mathrm{a}}$ & $0.233 \pm 0.010$
\end{tabular}

Data are presented as density of DKK $1 / \beta$-actin. ${ }^{\text {a }}<0.05$, vs. blank group.

Effect of DKK1 siRNA on EC cell invasion. Each field was observed under a light microscope (magnification, x20) and a significant difference was identified between the number of migrated cells in the DKK1 RNAi group (149.80) when compared with the blank group (122.50), and the knockdown of DKK1 was identified to result in accelerated EC cell invasion (Fig. 2).

Effect of DKK1 siRNA on EC cell migration. Cell migration numbers for DKK1 siRNA-treated and -untreated cells were 173.90 and 135.80 , respectively. The results indicated that the cells treated with DKK1 RNAi had significantly accelerated EC cell migration when compared with the blank group (Fig. 2).

$\beta$-catenin and MMP14 mRNA expression following knockdown of DKK1. The mRNA levels of $\beta$-catenin and MMP14 were increased in the DKK1 siRNA-treated cells when compared with the untreated and control-treated cells after $72 \mathrm{~h}$. In addition, the mRNA levels of $\beta$-catenin and MMP14 were significantly elevated following the knockdown of DKK1, however, no significant differences were identified in the blank and control groups (Fig. 3 and Tables III and IV). 

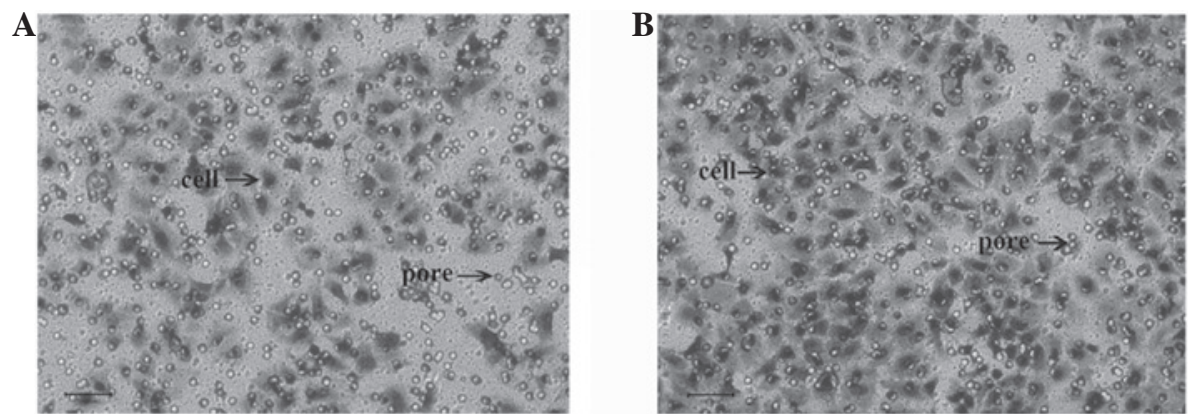

$\mathbf{C}$
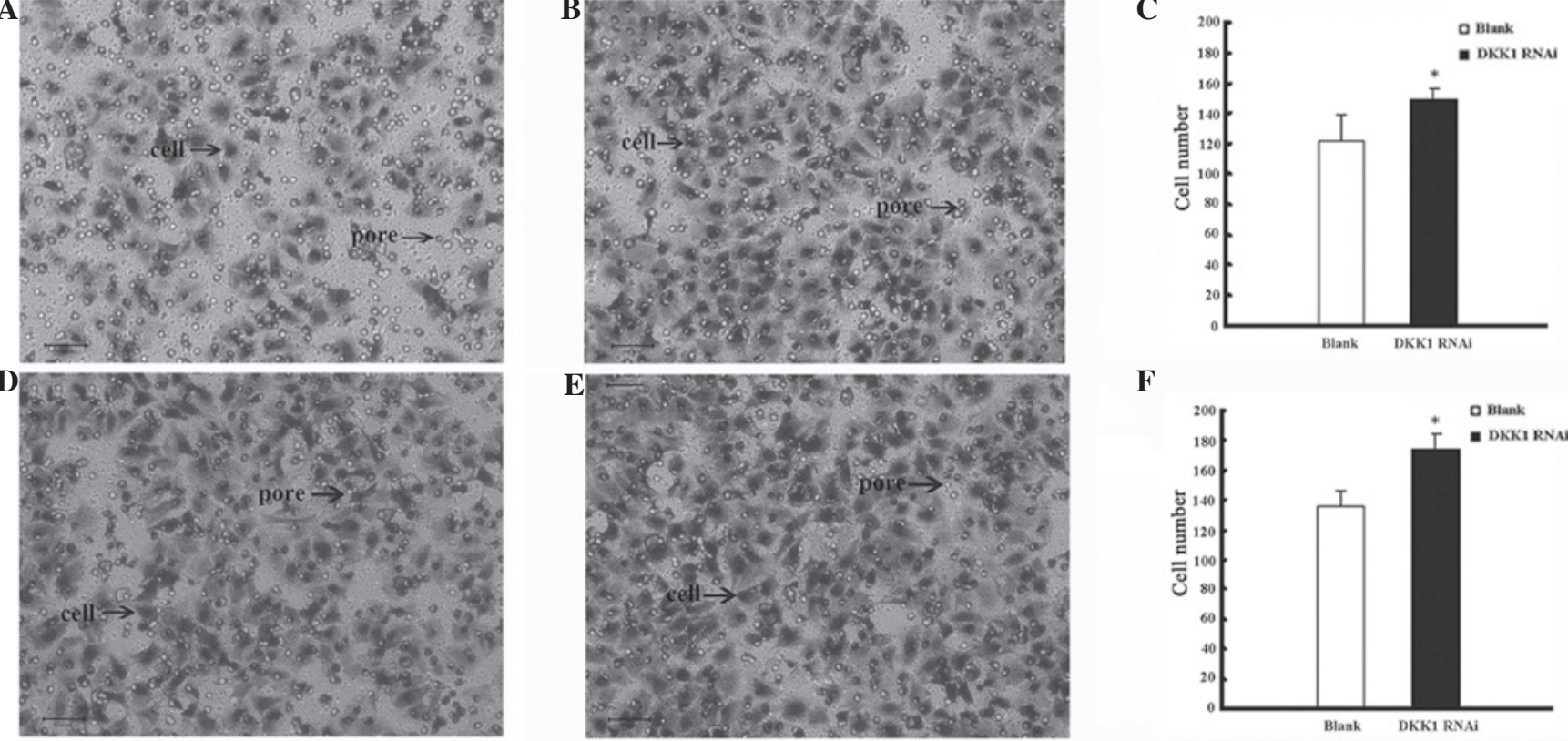

$\mathbf{F}$

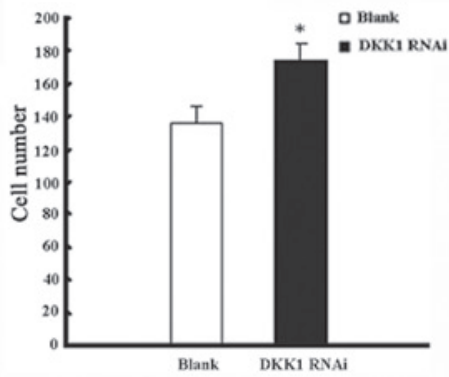

Figure 2. Invasion and migration assays were performed using the transwell chamber assay. Migrated cells stained with HE were counted by light microscope (magnification, x20) from randomly selected fields. Invasion assay (A) blank and (B) DKK1 RNAi groups. (C) Transfection with DKK1 siRNA, average cell number (149.80) penetrating the Matrigel matrix and pores was significantly increased when compared with that of the blank group (122.50), and cell invasion was elevated by 22.29\%. Migration assay (D) blank and (E) DKK1 RNAi groups. (F) Transfection of DKK1 siRNA, average cell number (173.90) penetrating the pores was significantly increased when compared with the blank group (135.80), and cell migration was elevated by $28.06 \%$. ${ }^{*}<<0.05$, vs. blank group. Bar indicates $50 \mu \mathrm{m}$. HE, hematoxylin and eosin.
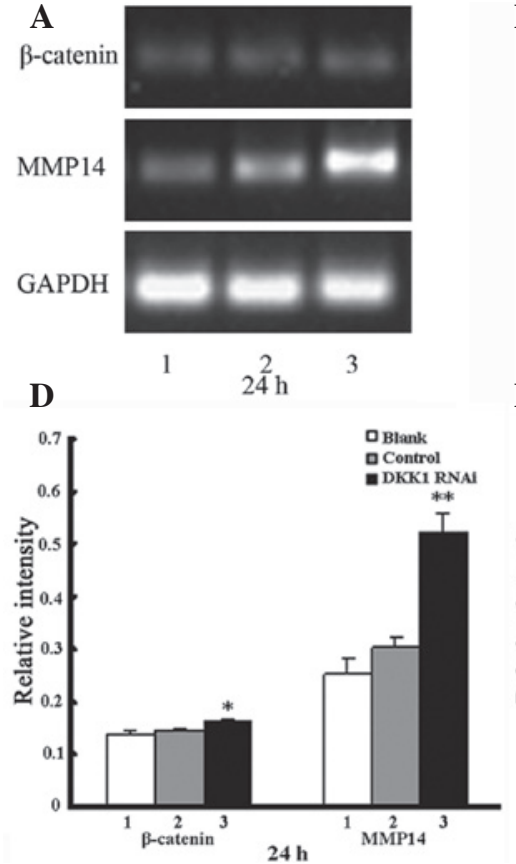
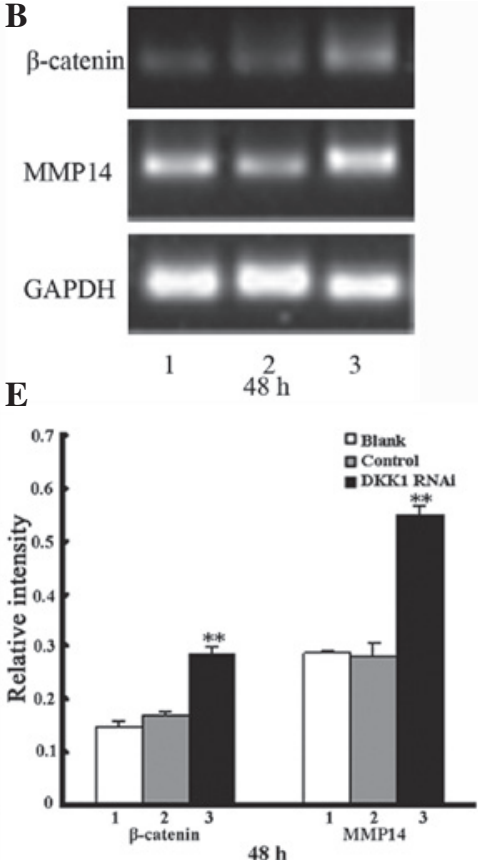

C

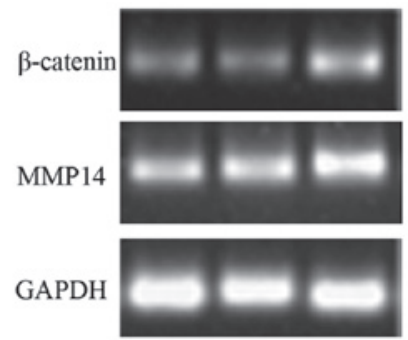

F
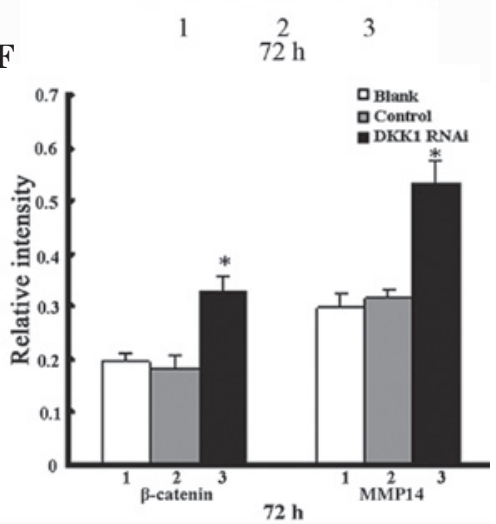

Figure 3. RT-PCR analyses of $\beta$-catenin and MMP14 mRNA expression in the three groups at (A) 24 , (B) 48 and (C) 72 h. (D-F) Data are presented as density of $\beta$-catenin or MMP14/GAPDH. ${ }^{*} \mathrm{P}<0.05$ and ${ }^{* *} \mathrm{P}<0.001$, vs. blank group. 1, blank; 2, control; and 3, DKK1 RNAi groups. MMP14, metallopeptidase 14; RNAi, RNA interference.

$\beta$-catenin and MMP14 protein expression following DKK1 knockdown. Western blot analyses of cell lysates were performed to analyze whether protein expression correlated with mRNA expression following the knockdown of DKK1. The protein levels of $\beta$-catenin and MMP14 in the DKK1 RNAi group were significantly elevated after $96 \mathrm{~h}$ when compared with that of the additional two groups (Fig. 4 and Tables V and VI), and no significant differences were identified in the protein levels of the blank and control groups. 

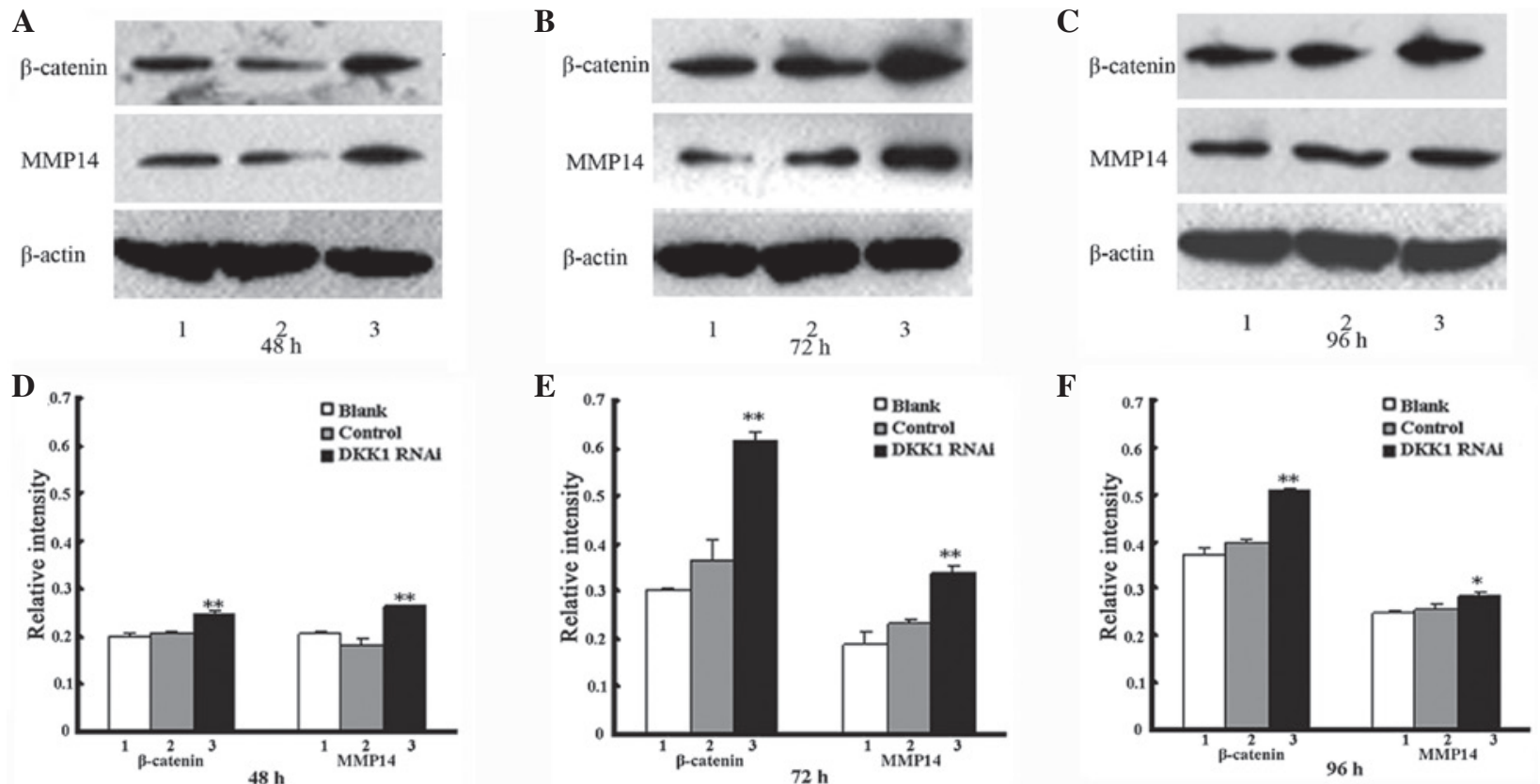

Figure 4. Western blot analyses of active- $\beta$-catenin and MMP14 protein expression in the three groups at (A) 48, (B) 72 and (C) $96 \mathrm{~h}$. (D-F) Data are presented as density of $\beta$-catenin or MMP14/ $\beta$-actin. ${ }^{*} \mathrm{P}<0.05$ and ${ }^{* *} \mathrm{P}<0.001$, vs. blank group. 1 , blank; 2 , control and 3, DKK1 RNAi groups. MMP14, metallopeptidase 14; RNAi, RNA interference.

Table III. Active $\beta$-catenin mRNA expression following knockdown of DKK1 at 24, 48 and $72 \mathrm{~h}$.

\begin{tabular}{lccc}
\hline Groups & $24 \mathrm{~h}$ & \multicolumn{1}{c}{$48 \mathrm{~h}$} & $72 \mathrm{~h}$ \\
\hline Blank & $0.137 \pm 0.006$ & $0.147 \pm 0.012$ & $0.195 \pm 0.015$ \\
Control & $0.144 \pm 0.002$ & $0.169 \pm 0.006$ & $0.182 \pm 0.024$ \\
DKK1 RNAi & $0.162 \pm 0.006^{\mathrm{a}}$ & $0.283 \pm 0.016^{\mathrm{b}}$ & $0.325 \pm 0.035^{\mathrm{a}}$
\end{tabular}

Data are presented as density of $\beta$-catenin/GAPDH. ${ }^{\mathrm{a} P}<0.05$ and ${ }^{\mathrm{b}} \mathrm{P}<0.001$, vs. blank group.

Table IV. MMP14 mRNA expression following knockdown of DKK1 at 24, 48 and $72 \mathrm{~h}$.

\begin{tabular}{lccc}
\hline Groups & $24 \mathrm{~h}$ & $48 \mathrm{~h}$ & $72 \mathrm{~h}$ \\
\hline Blank & $0.252 \pm 0.029$ & $0.287 \pm 0.005$ & $0.296 \pm 0.026$ \\
Control & $0.303 \pm 0.017$ & $0.282 \pm 0.022$ & $0.314 \pm 0.015$ \\
DKK1 RNAi & $0.162 \pm 0.006^{\mathrm{a}}$ & $0.283 \pm 0.016^{\mathrm{a}}$ & $0.532 \pm 0.044^{\mathrm{b}}$
\end{tabular}

Data are presented as density of MMP14/GAPDH. ${ }^{\mathrm{a}} \mathrm{P}<0.001$ and ${ }^{\mathrm{b}} \mathrm{P}<0.05$, vs. blank group. MMP14, metallopeptidase 14 .

\section{Discussion}

EC is the most common malignant tumor in females and has a high incidence worldwide (1). The majority of EC cases are metastatic at diagnosis and therefore, metastasis is the main cause of cancer-related mortality. Tumor cell invasion is a complex event that involves interactions among tumor cells, extracellular matrix (ECM) degradation and cell migration (2).
Table V. Active- $\beta$-catenin protein expression following knockdown of DKK1 at 48, 72 and $96 \mathrm{~h}$.

\begin{tabular}{lccc}
\hline Groups & $48 \mathrm{~h}$ & $72 \mathrm{~h}$ & $96 \mathrm{~h}$ \\
\hline Blank & $0.200 \pm 0.005$ & $0.301 \pm 0.004$ & $0.373 \pm 0.014$ \\
Control & $0.207 \pm 0.003$ & $0.366 \pm 0.045$ & $0.398 \pm 0.007$ \\
DKK1 RNAi & $0.244 \pm 0.007^{\mathrm{a}}$ & $0.618 \pm 0.017^{\mathrm{a}}$ & $0.510 \pm 0.005^{\mathrm{a}}$
\end{tabular}

Data are presented as density of $\beta$-catenin $/ \beta$-actin. ${ }^{a} \mathrm{P}<0.001$, vs. blank group; ${ }^{\text {b }}<0.001$, vs. blank group.

Table VI. MMP14 protein expression following knockdown of DKK1 at 48,72 and $96 \mathrm{~h}$.

\begin{tabular}{lccc}
\hline Groups & $48 \mathrm{~h}$ & $72 \mathrm{~h}$ & $96 \mathrm{~h}$ \\
\hline Blank & $0.206 \pm 0.005$ & $0.188 \pm 0.026$ & $0.247 \pm 0.005$ \\
Control & $0.181 \pm 0.015$ & $0.231 \pm 0.009$ & $0.255 \pm 0.010$ \\
DKK1 RNAi & $0.262 \pm 0.003^{\mathrm{a}}$ & $0.339 \pm 0.015^{\mathrm{a}}$ & $0.285 \pm 0.006^{\mathrm{b}}$
\end{tabular}

Data are presented as density of MMP14/ $\beta$-actin. ${ }^{\mathrm{a}} \mathrm{P}<0.001$, vs. blank group; ${ }^{\text {b }}<0.05$, vs. blank group. MMP14, metallopeptidase 14 .

Cell migration and invasion are early steps in metastasis (3) and therefore it is necessary to identify specific molecules and proteins that may limit the process of cell invasion and migration.

Previous studies have identified that abnormalities in the Wnt signaling transduction pathway contribute to tumorigenesis involved in cell migration, invasion and metastasis (4-8). A number of molecules and proteins involved in the Wnt 
signaling pathway have been investigated as targets for the diagnosis and treatment of malignant tumors. The present study focused on DKK1, a negative regulator in the Wnt signaling pathway $(12,13)$, as a key factor previously identified to be involved in the invasion and migration of colorectal (14), neuroblastoma (15) and placental cells $(16,17)$.

$\beta$-catenin functions as a significant component in the Wnt signaling pathway, and interactions with frizzled and LRP5/6 receptors result in the dephosphorylation of $\beta$-catenin (non-phosphorylated active $\beta$-catenin). The dephosphorylated form of $\beta$-catenin has been shown to have significant effects on the Wnt signaling pathway $(18,19)$. Subsequent to these interactions, accumulated active- $\beta$-catenin molecules translocate to the nucleus, activating downstream target genes, the majority of which, including the MMPs, are involved in tumorigenesis (20-23). The MMP family is comprised of zinc-dependent endopeptidases that are crucial for various proteolytic events and a number of tumor malignancy processes, including metastasis (24). MMPs are also involved in ECM degradation and therefore contribute to tumor progression and metastasis. Previous studies have shown that during tumorigenesis, MMPs are involved in tumor migration, metastasis and invasion into surrounding tissue. MMP14 is a member of the MMP family and has been identified to be involved in ECM degradation and invasion. In addition, the human DKK1 (chromosome 10q11.2) gene encodes an inhibitor involved in the Wnt signaling pathway, binding to and antagonizing LRP5/6 (25-27). In the present study, the hypothesized interactions between $\beta$-catenin, MMP14 and DKK1 in EC cell invasion and migration were investigated.

RNAi is a sequence-specific, post-transcriptional gene-silencing method initiated by double-stranded RNA and homologous to the gene being suppressed. RNAi is now routinely used for the transient knockdown of gene expression in a wide range of organisms for the analysis of gene function (28). In the present study, siRNA with high specificity and efficiency to DKK1 were used to suppress DKK1 gene expression in Ishikawa EC cells. In addition, DKK1, $\beta$-catenin and MMP14 were targeted using DKK1-targeting siRNA to identify the effects of DKK1 on EC cell invasion and migration. Few studies have analyzed the biology of DKK1 function in tumor invasion and migration.

In the present study, the transfection of DKK1 siRNA downregulated the mRNA and protein levels of DKK1 in the DKK1 RNAi group. DKK1 siRNA was identified to significantly inhibit DKK1 mRNA levels after $48 \mathrm{~h}$, and protein levels were downregulated after $72 \mathrm{~h}$. However, no marked changes in the levels of mRNA and protein were identified in the blank and control groups. These results demonstrated that the mRNA and protein levels of DKK1 were successfully downregulated by transfection of DKK1 siRNA, however, no significant decrease in the levels of $\mathrm{mRNA}$ and protein were identified in the DKK1 siRNA-treated cells after 72 and $96 \mathrm{~h}$, respectively. This is hypothesized to be due to the transient nature of the DKK1-knockdown by DKK1 siRNA.

The knockdown of DKK1 has been identified to accelerate EC cell invasion and migration. In the present study, EC cells transfected with DKK1 siRNA showed increased tumor cell invasion and migration when compared with the untreated and control-treated cells, indicating an upregulation of $\beta$-catenin and MMP14. A significant increase in the mRNA and protein levels of $\beta$-catenin and MMP14 and cell invasion and migration were identified in the DKK1 RNAi group when compared with the additional two groups. The results of the current study are consistent to that of previous studies reporting the involvement of the knockdown of DKK1 in tumor cell invasion and migration (15-18). In addition, these were consistent with the results of our previous study, which demonstrated that EC cell invasion and migration may be inhibited by the upregulation of DKK1 (29-31).

Upregulation of $\beta$-catenin and MMP14 by the knockdown of DKK1 interferes with the Wnt signaling pathway and its downstream signaling events. Intracellular signaling transduction pathways are often exploited during tumor invasion and migration and the involvement of $\beta$-catenin and MMP14 in the Wnt signaling transduction pathway has been identified to accelerate tumor invasion and migration. Therefore, the hypothesized effects of the DKK1 RNAi-mediated upregulation of $\beta$-catenin and MMP14 on EC cell migration and invasion were investigated in the present study. A significant increase in the levels of $\beta$-catenin mRNA and protein in the DKK1 RNAi group was identified. The knockdown of DKK1 increased the levels of $\beta$-catenin dephosphorylation into active- $\beta$-catenin, which resulted in elevated activation of the Wnt signaling pathway. Accumulated active- $\beta$-catenin in the cytoplasm was translocated into the nucleus where it interacted with lymphocyte enhancers and T-cell transcription factors to activate downstream target genes, including MMP14. Marked increases in the MMP14 mRNA and protein levels in the DKK1 RNAi group indicated significant MMP14 activation. The results indicated that the upregulation of $\beta$-catenin and MMP14 the knockdown of DKK1 may result in the elevated activation of the Wnt signaling pathway and downstream signaling events involved in tumor migration and invasion.

In summary, the results of the present study indicate a novel biological function for DKK1 in the inhibition of EC cell invasion and migration. In addition, targeting DKK1 may represent an effective anti-invasion and -migration strategy for the treatment of EC, as DKK1 may contribute directly or indirectly to anti-tumorigenesis.

\section{References}

1. Akhmedkhanov A, Zeleniuch-Jacquotte A and Toniolo P: Role of exogenous and endogenous hormones in endometrial cancer: review of the evidence and research perspectives. Ann NY Acad Sci 943: 296-315, 2001.

2. Arai $\mathrm{Y}$, Kubota $\mathrm{T}$, Nakagawa $\mathrm{T}$, et al: Production of urokinase-type plasminogen activator (u-PA) and plasminogen activator inhibitor-1 (PAI-1) in human brain tumours. Acta Neurochir (Wien) 140: 377-386, 1998.

3. Bogenrieder T and Herlyn M: Axis of evil: molecular mechanisms of cancer metastasis. Oncogene 22: 6524-6536, 2003.

4. Terstappen GC, Gaviraghi G and Caricasole A: The Wnt signaling pathway as a target for the treatment of neurodegenerative disorders. IDrugs 9: 35-38, 2006.

5. Bienz $M$ and Clevers $H$ : Linking colorectal cancer to Wnt signaling. Cell 103: 311-320, 2000.

6. Collavin L and Kirschner MW: The secreted Frizzled-related protein Sizzled functions as a negative feedback regulator of extreme ventral mesoderm. Development 130: 805-816, 2003.

7. Mao B, Wu W, Li Y, et al: LDL-receptor-related protein 6 is a receptor for Dickkopf proteins. Nature 411: 321-325, 2001.

8. Aravind L and Koonin EV: A colipase fold in the carboxy-terminal domain of the Wnt antagonists - the Dickkopfs. Curr Biol 8: R477-R478, 1998. 
9. Müller A, Homey H, Soto H, et al: Involvement of chemokine receptors in breast cancer metastasis. Nature 410: 50-56, 2001.

10. Staun RE, Goldman S, Gabarin D, et al: Expression and importance of matrix metalloproteinase 2 and 9 (MMP-2 and -9) in human trophoblast invasion. Reprod Biol Endocrinol 2: 59, 2004.

11. Staff AC, Ranheim T, Henriksen T, et al: 8-Iso-prostaglandin $\mathrm{f}$ (2alpha) reduces trophoblast invasion and matrix metalloproteinase activity. Hypertension 35: 1307-1313, 2000.

12. Fedi P, Bafico A, Nieto SA, et al: Isolation and biochemical characterization of the human Dkk-1 homologue, a novel inhibitor of mammalian Wnt signaling. J Biol Chem 274: 19465-19472, 1999.

13. Bafico A, Liu G, Goldin L, Harris V and Aaronson SA: An autocrine mechanism for constitutive Wnt pathway activation in human cancer cells. Cancer Cell 6: 497-506, 2004

14. Maehata T, Taniguchi H, Yamamoto H, et al: Transcriptional silencing of Dickkopf gene family by $\mathrm{CpG}$ island hypermethylation in human gastrointestinal cancer. World J Gastroenterol 14: 2702-2714, 2008.

15. Koppen A, Ait-Aissa R, Hopman S, et al: Dickkopf-1 is down-regulated by MYCN and inhibits neuroblastoma cell proliferation. Cancer Lett 256: 218-228, 2007.

16. Pollheimer J, Loregger T, Sonderegger S, et al: Activation of the canonical wingless/T-cell factor signaling pathway promotes invasive differentiation of human trophoblast. Am J Pathol 168: 1134-1147, 2006.

17. Grisaru-Granovsky S, Maoz M, Barzilay $\mathrm{O}$, et al: Protease activated receptor-1, PAR1, promotes placenta trophoblast invasion and beta-catenin stabilization. J Cell Physiol 218 : $512-521,2009$

18. Mao J, Wang J, Liu B, et al: Low-density lipoprotein receptor-related protein-5 binds to Axin and regulates the canonical Wnt signaling pathway. Mol Cell 7: 801-809, 2001

19. Giles RH, van Es JH and Clevers H: Caught up in a Wnt storm: Wnt signaling in cancer. Biochim Biophys Acta 1653: 1-24, 2003

20. Crawford HC, Fingleton BM, Rudolph-Owen LA, et al: The metalloproteinase matrilysin is a target of beta-catenin transactivation in intestinal tumors. Oncogene 18: 2883-2891, 1999.
21. Tetsu $\mathrm{O}$ and McCormick F: Beta-catenin regulates expression of cyclin D1 in colon carcinoma cells. Nature 398: 422-426, 1999.

22. Polakis P: Wnt signaling and cancer. Genes Dev 14: 1837-1851, 2000.

23. Bafico A, Liu G, Yaniv A, Gazit A and Aaronson SA: Novel mechanism of Wnt signalling inhibition mediated by Dickkopf-1 interaction with LRP6/Arrow. Nat Cell Biol 3: 683-686, 2001.

24. Ichikawa Y, Ishikawa T, Tanaka K, Togo S and Shimada H: Extracellular matrix degradation enzymes: important factors in liver metastasis of colorectal cancer and good targets for anticancer metastatic therapy. Nihon Geka Gakkai Zasshi 102: 376-380, 2001 (In Japanese).

25. González-Sancho JM, Aguilera O, García JM, et al: The Wnt antagonist DICKKOPF-1 gene is a downstream target of beta-catenin/TCF and is downregulated in human colon cancer. Oncogene 24: 1098-1103, 2005.

26. Mao B and Niehrs C: Kremen2 modulates Dickkopf2 activity during Wnt/LRP6 signaling. Gene 302: 179-183, 2003.

27. Logan CY and Nusse R: The Wnt signaling pathway in development and disease. Annu Rev Cell Dev Biol 20: 781-810, 2004.

28. Holen T, Amarzguioui M, Babaie E and Prydz H: Similar behaviour of single-strand and double-strand siRNAs suggests they act through a common RNAi pathway. Nucleic Acids Res 31: 2401-2407, 2003.

29. Yi N, Liao QP, Li T and Xiong Y: Novel expression profiles and invasiveness-related biology function of DKK1 in endometrial carcinoma. Oncol Rep 21: 1421-1427, 2009.

30. Yi N, Liao QP and Li T: Expression and influence of Dickkopf1 on invasion ability in endometrial carcinoma. Xian Dai Fu Chan Ke Jin Zhan Bian Ji Bu 2: 113-116, 2009.

31. Yi N, Liao QP, Xue XO and Liu M: Expression of Dickkopf-1 in endometrial carcinoma and normal endometrial tissues and its clinicopathological significance. Zhong Guo Quan Ke Yi Xue Bian Ji Bu 9: 981-983, 2011. 